九州大学学術情報リポジトリ

Kyushu University Institutional Repository

\title{
Reconstruction of Phylogenetic Relationships of Korean Chickens Using Mitochondrial D-Loop Sequences
}

Hoque, Md. Rashedul

Department of Animal Science and Biotechnology, Chungnam National University

Seo, Dong-Won

Department of Animal Science and Biotechnology, Chungnam National University

Jo, Cheorun

Department of Animal Science and Biotechnology, Chungnam National University

Gotoh, Takafumi

Kuju Agriculture Research Center, Kyushu University

他

https://doi.org/10.5109/27359

出版情報 : 九州大学大学院農学研究院紀要. 58 (2)，pp. 287-293，2013-09. 九州大学大学院農学研究院 バージョン：

権利関係: 


\title{
Reconstruction of Phylogenetic Relationships of Korean Chickens Using Mitochondrial D-loop Sequences
}

\author{
Md. Rashedul HOQUE ${ }^{1}$, Dong-Won SEO ${ }^{1}$, Cheorun JO$^{1}$, \\ Takafumi GOTOH ${ }^{2}$ and Jun-Heon LEE $^{1 *}$
}

\author{
Kuju Agriculture Research Center, Kyushu University, Oita, 878-0201, Japan
}

(Received April 26, 2013 and accepted May 9, 2013)

\begin{abstract}
Two hypotheses of monophyletic and multiple origins have been documented for chicken domestication. The maternally inherited D-loop region in mtDNA is widely used for the investigation of relationships between populations and individuals of various animal species. In this study, 854 Korean chicken mtDNA D-loop sequences were investigated. Thirty five nucleotide substitutions were identified from the sequence analyses, and they were classified as twenty eight haplotypes. Phylogenetic analyses revealed five divergent mtDNA clades (A to E) based on geographical distribution. There was no breed specific clade among the Korean chickens. Moreover, the estimation of network profiles was traced using 28 haplotypes and five mtDNA clades. Korean chickens were discriminated based on the nucleotide positions. The clades A, B, and $\mathrm{E}$ are distributed universally in Eurasia, and among them, 95.78\% Korean chickens were included. On the other hand, C and D clades were represented 2.34 and 1.87\% of Korean chickens, respectively. Our mtDNA results indicate that Korean chickens share mtDNA haplotypes with a number of chicken breeds from South China, Japan, Europe, Middle East and Indian subcontinent regions. Therefore, the results suggest that Korean chickens have multiple maternal origins.
\end{abstract}

Key words: clade, D-loop region, geographical origin, Korean chicken, phylogeny

\section{INTRODUCTION}

Korean chicken was first documented approximately 2,000 years ago, and about 20 breeds were present in the Joseon Dynasty (A. D. 1392-1910). However, during the Second World War, many breeds became extinct. In order to conserve native chicken breeds, the Korean government launched a conservation project in 1994, based on the collection of chickens from rural areas, and since then native chickens have been raised by the National Institute of Animal Science, and genetic selection process have been carried out, mainly in order to enhance economic traits and feather colors. As a consequence, five lines of Korean native chicken (KNC: black, red, yellow, gray and white) were described, and along with them, four additional breeds (Rhode Island Red, Cornish, White Leghorn and Ogye) are available for the commercial breeding of native chickens in Korea. Of these, three chicken breeds (RIR, Cornish, and White Leghorn), which were imported during the 1960's and 1970's, have been adapted as pure breeds in Korea. Therefore, the aim of this study is to review all the available Korean chickens, especially focusing on their phylogenetic relationships.

There are two hypotheses of the domestication of chickens within Korea, one is that they are of monophyletic origin and the other is that of multiple origins. Most researchers have reported that domestic chickens originated from the red jungle fowl (Gallus gallus) as a sole ancestor (Crawford, 1990; Moiseyeva, 1998). The first molecular genetic study of their mtDNA D-loop

\footnotetext{
Department of Animal Science and Biotechnology, Chungnam National University, Daejeon 305-764, Korea

Kuju Agriculture Research Center, Kyushu University

* Corresponding author (E-mail: junheon@cnu.ac.kr)
}

region suggested a monophyletic origin, with a red jungle fowl subspecies as the sole ancestor of all domestic chickens (Fumihito et al., 1996, 1994). However, there were some limitations of that study, based on the small numbers of samples of both domestic and wild subspecies of red jungle fowl from China and India, and the small sample sizes for the analysis (Fumihito et al., 1994). Consequently, analysis of the mtDNA of Chinese native chickens confirmed that they originated in Thailand and its adjacent geographic areas (Niu et al., 2002). Besides, genetic evidence had previously been documented for chicken domestication from multiple progenitors (Nishibori et al., 2005). Also, variability in D-loop region of geographical distributions was suggested as evidence for chicken domestication from multiple origins (Liu et al., 2006). Previous results have indicated that five progenitor subspecies may have contributed to modern chicken domestication in five different regions; G. g. gallus in Thailand and its adjacent regions, G. g. spadiceus in Burma and Yunnan Province of China, G. g. jabouillei in Southern China and Vietnam, G. g. murghi in India, and G. g. bankiva in the Java Islands (Crawford, 1990, 1995; Delacour, 1957; Howard and Moore, 1984). However, there is no clear evidence the origin of modern domesticated chickens.

In the mitochondrial genome, the non-coding control (D-loop) region is used for inter-specific population studies (Baker and Marshall, 1997; Moore and Defilippis, 1997) for the advantages of the absence of recombination and rapid nucleotide substitutions compared with genomic DNA sequences (Aquadro and Greenberg, 1983; Cann et al., 1984; Lansman et al., 1983). The investigation of chicken D-loop sequences was previously determined to inspect the origin of breeds or species, and various haplotypes have been reported (Komiyama et al., 
2003, 2004; Liu et al., 2006; Oka et al., 2007). Also, the mtDNA haplotypes of Korean chickens have been determined for the purposes of breed discrimination and determining the origin of domestication (Lee et al., 2007; Hoque et al., 2009, 2011, 2012). The aim of this study is to review the total haplotypes and geographical distribution of all Korean chickens using previously identified mtDNA D-loop sequences. Also, this study should aid our understanding of the origin of Korean chickens, which may help future appropriate conservation breeding programs, and the improvement of the Korean poultry industry.

\section{MATERIALS AND METHODS}

\section{Individuals used in this study}

A total of 802 sequences from ten chicken breeds/ populations and individuals were included in this study. These sequence data were previously published for the genetic discrimination of Korean native chicken populations (Hoque et al., 2009, 2011, 2012). These sequences belong to 67 haplotypes and are deposited in GenBank under the inclusive accession numbers of KC218503 to KC218569. Also, 52 published sequences (HQ836343 to HQ836363 and DQ629864 to DQ629894) from GenBank were also included in our analysis. A total of 854 individuals from fourteen breeds/populations were examined in this study (Table 1).

\section{Sequence analyses}

The chicken mtDNA D-loop nucleotide sequence data were aligned using the ClustalW program (Thompson et al., 1994). Nucleotide replacement export data from mtDNA were carried out in haplotype sequences by using MEGA5 (Tamura et al., 2011). The number of haplotypes, nucleotide variable sites, haplotype diversity and nucleotide diversity (Nei, 1982) were calculated using DnaSP V.5.10 (Rozas et al., 2003). A rectangular Kimura 2-parameter model neighbor-joining (NJ) phylogenetic tree with 1,000 bootstrap replications was constructed for identification of the clades using MEGA5. Also, an outline for median-joining network profiles with positional SNPs for the differentiation of haplotypes was prepared by using NETWORK4610 software (Bandelt et al., 1999).

Table 1. The calculated number of variable sites (S), number of haplotypes (h), haplotype diversity (Hd) and nucleotide diversity (Pi) using mitochondrial D-loop sequence polymorphisms for the Korean chickens

\begin{tabular}{|c|c|c|c|c|c|}
\hline Breed/Population ${ }^{1}$ & Sample no. & $\mathrm{S}^{2}$ & $\mathrm{H}^{2}$ & $\mathrm{Hd}^{2}$ & $\mathrm{Pi}^{2}$ \\
\hline Rhode Island Red (RIR) & 140 & 17 & 7 & 0.494 & 0.0078 \\
\hline Cornish & 83 & 17 & 11 & 0.744 & 0.0113 \\
\hline Korean native chicken black & 33 & 22 & 11 & 0.845 & 0.0138 \\
\hline Korean native chicken red & 33 & 19 & 6 & 0.68 & 0.0124 \\
\hline Korean native chicken yellow & 36 & 22 & 9 & 0.716 & 0.0115 \\
\hline Ogye & 32 & 16 & 6 & 0.786 & 0.0136 \\
\hline White Leghorn & 1 & 0 & 1 & 0 & 0 \\
\hline Korean Longtail A & 1 & 0 & 1 & 0 & 0 \\
\hline Jeju breed & 3 & 7 & 3 & 1 & 0.0105 \\
\hline Hyunin & 272 & 17 & 6 & 0.768 & 0.0083 \\
\hline 5 Woorimatdag populations & 135 & 22 & 7 & 0.342 & 0.0046 \\
\hline Parent stock of Woorimatdag (K) & 26 & 0 & 1 & 0 & 0 \\
\hline Hanhyup-3 & 40 & 15 & 5 & 0.778 & 0.0068 \\
\hline Parent stock of Hanhyup-3 & 19 & 11 & 5 & 0.766 & 0.0049 \\
\hline Total & 854 & & & & \\
\hline \multicolumn{6}{|c|}{$\begin{array}{l}{ }^{1} \text { Rhode Island Red sequences have been published (Hoque et al., 2009, 2011), Cornish sequences have been published } \\
\text { (Hoque et al., 2009, 2011), Korean native chicken black sequences have been published (Hoque et al., 2011, 2012, } \\
\text { and GenBank Accession no: HQ836346, HQ836347, HQ836350, HQ836356, HQ836359), Korean native chicken red } \\
\text { sequences have been published (Hoque et al., 2011, 2012, and GenBank Accession no: HQ836351, HQ836358, } \\
\text { HQ836362), Korean native chicken yellow sequences have been published (Hoque et al., 2011, 2012, and GenBank } \\
\text { Accession no: HQHQ836343, HQ836348, HQ836349, HQ836355, HQ836357, HQ836360), Ogye sequences have been } \\
\text { published (DQ629864 to DQ629894), White Leghorn sequence has been published (HQ836353), Korean Longtail A } \\
\text { sequence has been published (HQ836352), Jeju breed sequences have been published (HQ836344, HQ836345, } \\
\text { HQ836361), Hyunin sequences have been published (Hoque et al., 2012), } 5 \text { Woorimatdag populations: K population } \\
\text { (37) sequences have been published (Hoque et al., 2011, 2012) and A (20), B (18), C (20), D (20) and K (20) } \\
\text { populations sequences have not published yet, Parent stock of Woorimatdag (K) sequences have been published } \\
\text { (Hoque et al., 2011, 2012), Hanhyup-3 sequences have been published (Hoque et al., 2011, 2012), Parent stock of } \\
\text { Hanhyup-3 sequences have been published (Hoque } \text { et al., 2011, 2012). } \\
{ }^{2} \text { S=number of variable sites, H=number of haplotype, Hd=haplotype diversity, Pi=nucleotide diversity. }\end{array}$} \\
\hline
\end{tabular}




\section{RESULTS AND DISCUSSION}

\section{Genetic diversity}

A total of 854 mtDNA D-loop sequences were used to calculate the number of variable sites $(\mathrm{S})$, number of haplotypes $(\mathrm{H})$, haplotype diversity $(\mathrm{Hd})$ and nucleotide diversity (Pi) among the chicken populations (Table 1). D-loop sequences of 140 individuals in RIR breed obtained 17 variable sites about 7 haplotypes, for which $\mathrm{Hd}$ and Pi values of 0.494 and 0.0078 , respectively, were calculated. The Cornish chicken breed was estimated as: S (17), H (11), Hd (0.744) and Pi (0.0113), respectively, based on 83 individuals. 32 Ogye sequences were collected from the GenBank database, obtaining 16 variable sites with 6 haplotypes which measured Hd (0.786) and Pi (0.0136). Previously, it has been reported that four haplotypes were found in the Korean Ogye chicken (Lee et al., 2007). Only one sequence was found in the GenBank database for the Korean White Leghorn breed. 33 sequences of KNC black were considered for the determination of S (22), H (11), Hd (0.845) and Pi (0.0138). Also, 33 sequences were observed in $\mathrm{KNC}$ red, for which $\mathrm{S}$ (19), H (6), Hd (0.68) and Pi (0.0124) were calculated. 36 sequences of KNC yellow were analyzed to obtain 22

Table 2. The identified haplotypes and clades with mitochondrial D-loop sequence polymorphisms among the Korean chickens

Nucleotide substitution of D-loop region

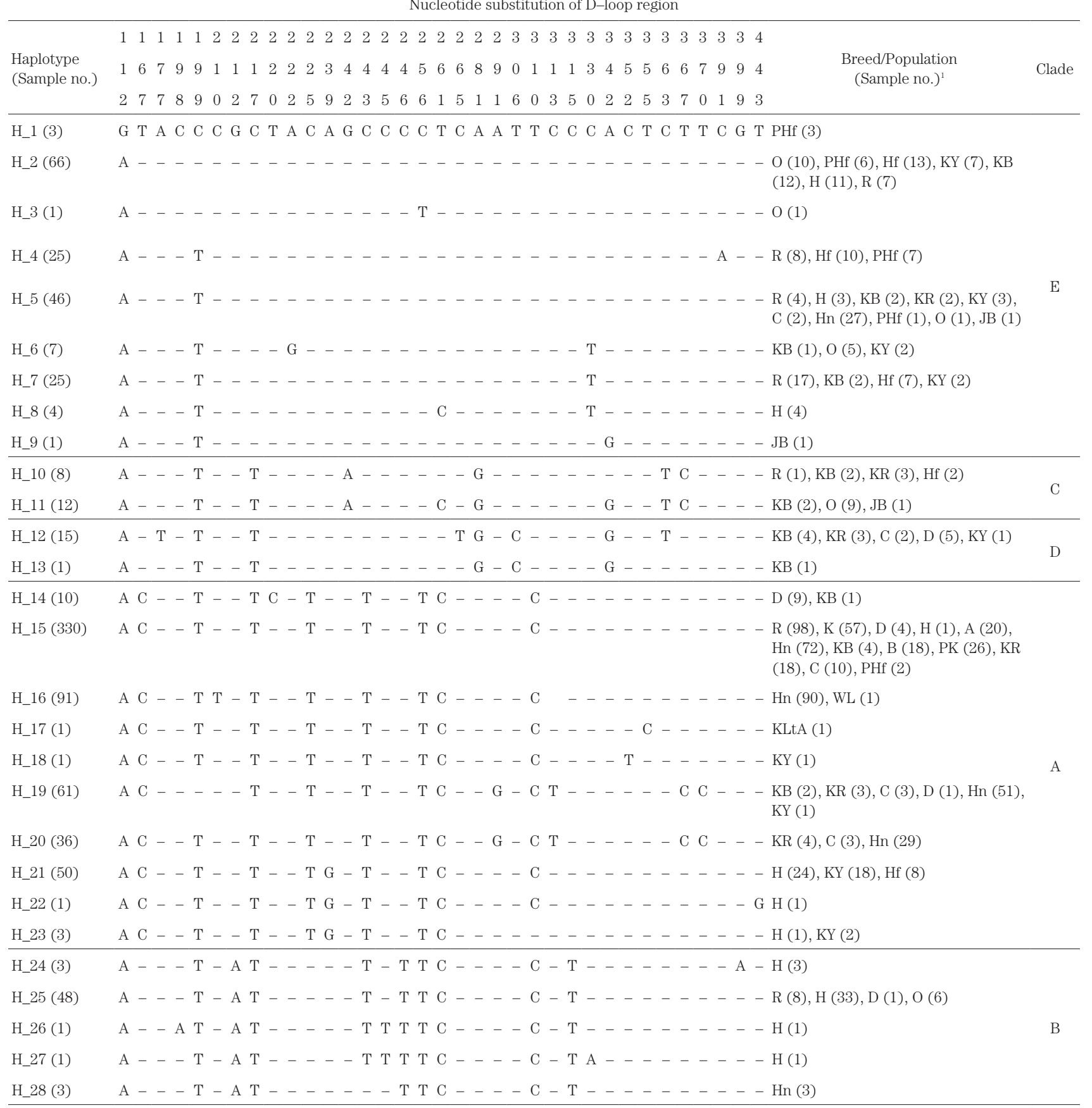

${ }^{1} \mathrm{R}=$ Rhode Island Red; $\mathrm{H}=$ Cornish; WL=White Leghorn; $\mathrm{O}=$ Ogye; $\mathrm{KB}=$ Korean black, KR=Korean red; KY=Korean yellow; JB=Jeju breed, KLtA=Korean Longtail A; Hn=Hyunin; A=Woorimatdag A; B=Woorimatdag B; C=Woorimatdag C; D=Woorimatdag D; K=Woorimatdag K; PK=Parent stock of Woorimatdag $\mathrm{K} ; \mathrm{Hf}=$ Hanhyup $-3 ; \mathrm{PHf}=$ Parent stock of Hanhyup -3 . 
variable sites with 9 haplotypes, for which $\mathrm{Hd}$ (0.716) and $\mathrm{Pi}(0.0115)$ were calculated. Analysis of $272 \mathrm{mtDNA}$ D-loop sequence data from the Hyunin population from single flock revealed six haplotypes, comprised of seventeen nucleotide substitutions. All of the six mtDNA haplotypes for the Hyunin chicken population were discovered from chickens with ten different plumage colors. Based on statistical analysis, the identified $\mathrm{Hd}$ and $\mathrm{Pi}$ were 0.768 and 0.0083 , respectively, in Hyunin chickens. Three individuals from Jeju native chickens were identified, with $\mathrm{S}, \mathrm{H}, \mathrm{Hd}$ and $\mathrm{Pi}$ determined to be 7, 3, 1 and 0.0105 , respectively.

Korean longtail A (GenBank accession no. HQ836352) chicken was found only to contain one sequence for participation in our analyses. Two commercial Korean native chicken populations (Woorimatdag and Hanhyup) have recently been developed by crossing Korean native chickens with other commercial chicken breeds, in order to increase the meat content. Based on the continued crossing of chicken populations, five distinct Woorimatdag (A, $\mathrm{B}, \mathrm{C}, \mathrm{D}$ and $\mathrm{K}$ ) chicken populations have been developed in Korea. A total of 135 individuals from five distinct Woorimatdag populations obtained 22 variable sites with 7 haplotypes for which we calculated $\mathrm{Hd}$ and Pi of 0.342 and 0.0046, respectively. Besides, 26 individuals of parent stock of Woorimardag $\mathrm{K}$ were obtained for just one haplotype. Hanhyup-3 commercial chicken population obtained 40 sequences to calculate $\mathrm{S}, \mathrm{H}, \mathrm{Hd}$ and $\mathrm{Pi}$ values of $15,5,0.778$ and 0.0068 , respectively. Also, 19 sequences of parent stock of Hanhyup-3 obtained 11 variable sites with 5 haplotypes for which $\mathrm{Hd}$ and Pi values of 0.766 and 0.0049 , respectively, were calculated. Comparatively, KNC black conveyed the highest value for $\mathrm{Hd}$ and $\mathrm{Pi}$ (0.845 and 0.0138, respectively). However, a high value of $\mathrm{Hd}(0.964)$ was also documented in Laiwa black Chinese native chickens (Liu et al., 2010).

\section{Phylogeny of the haplotypes and network profiles}

Hence, analyses of 854 mtDNA D-loop sequences in Korean chickens from fourteen populations identified 35 nucleotide variations, which were classified into 28 haplotypes (Table 2). Previous studies identified nine highly divergent mtDNA clades (A-I) from 169 haplotypes, using the red jungle fowls and domestic chickens (Liu et al., 2006). This study identified 28 haplotypes, and clades using 44 sequences were constructed for phylogenetic analyses of Korean chickens (Figure 1). While, four clades (F, G, H and I) are absent of haplotypes in Korean chickens, the phylogenetic analyses revealed five highly divergent mtDNA clades (A-E). Phylogenetic analysis revealed that Korean chickens were domesticated from continental chickens breed. Among these 28 haplotypes, H_1 to H_9, H_10 to H_11, H_12 to H_13, H_14 to H_23, and H_24 to H_28 belonged to clades E, C, D, A, and B,

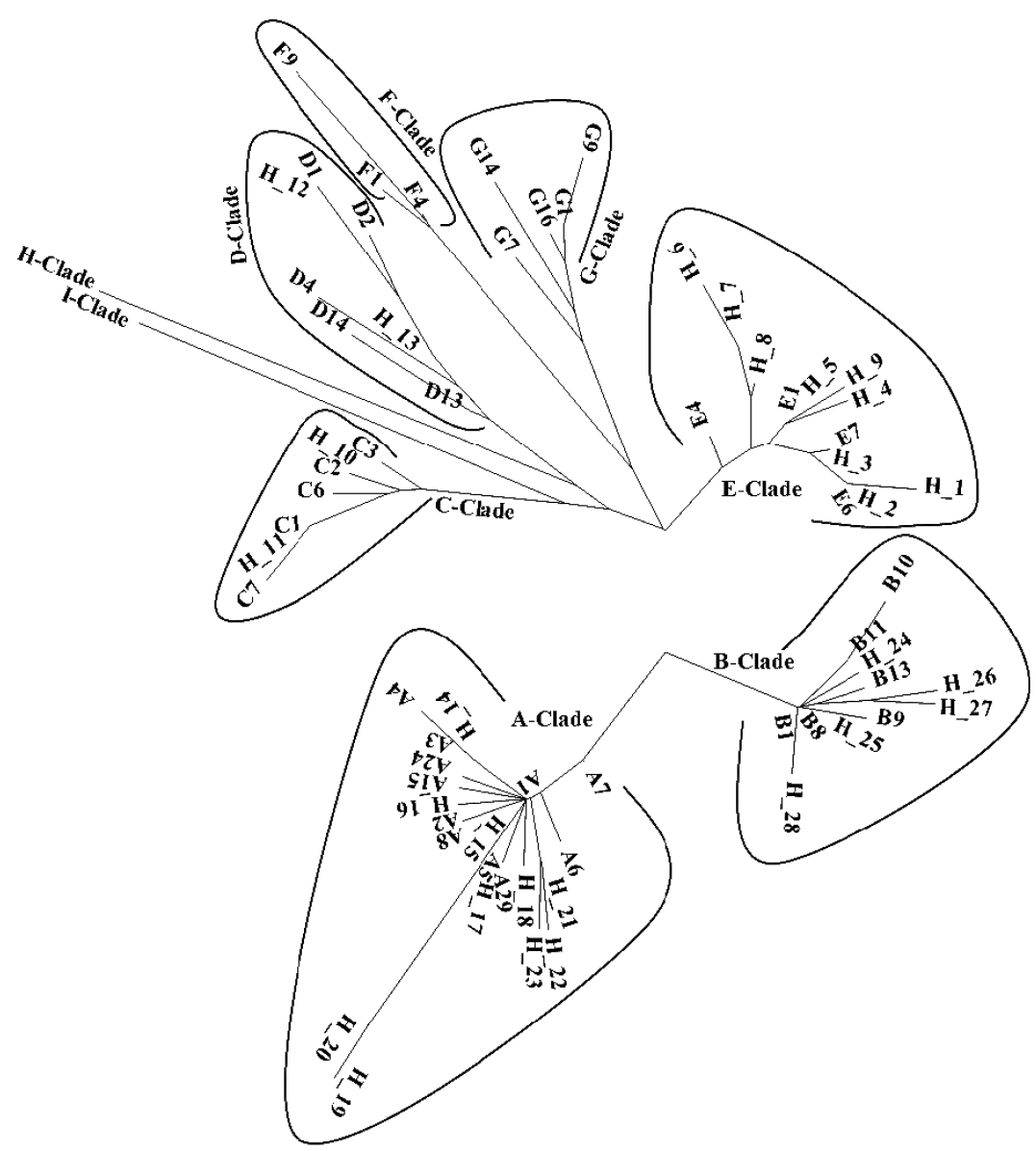

Fig. 1. The construction of phylogenetic analyses to identify the clades using 28 haplotypes and reported haplotypes by Liu et al. (2006) 
respectively. H_15 contained 330 samples (38.64\%), which was the highest among all haplotypes. The A clade contains more individuals than any other clade. Previously, Liu et al. (2006) described the origin of chickens which represented A and B clades from South China and Japanese chickens. However, the E clade represents the regions of Europe, the Middle East and the Indian subcontinent. Previous documentation of the clades A, B and E describes them as being distributed ubiquitously in Eurasia, and Korean chickens are widely distributed within these clades. Around 20 samples represent the $\mathrm{C}$ clade, which extensively originated from Japanese chickens. Also, 16 samples belong to the D clade, which is composed of red jungle fowl and domestic chickens mainly from India and Indonesia (Liu et al., 2006)

Consequently in this analysis, A, B, and F clades were suggested as being from the continental subspecies, $G$. g. spadiceus and G. g. jabouillei, whereas samples from G. g. gallus were mostly observed in clades D, H, and I. Based on these results, chickens were domesticated from multiple origins, which conflicts with results from Fumihito et al. (1994, 1996) suggesting a single domestication event. Due to the countless human migrations and trade relations during the course of the history, A, $\mathrm{B}$, and $\mathrm{E}$ clades are widely distributed, which suggests that Korean chickens were domesticated from multiple maternal origins.

Moreover, the estimation of network profiles was traced using 28 haplotypes inside five mtDNA clades, which were discriminated by nucleotide positions of
Korean chickens (Figure 2). These nucleotide positions can be used as markers for clade differentiation. The clades were not differentiated according to the specific chicken breed, but will be useful for the demarcation of regional chickens. Our results provide a clear concept for the origin of domestication in Korean chickens, which will help for the further improvement of Korean chickens.

\section{Breed and population distribution in the clade}

A total of fourteen chicken breeds/populations were distributed in the identified five clades (Table 3). The geographical distribution clades of Korean chickens A, B, C, D and E contained 584 (68.38\%), 56 (6.56\%), 20 (2.34\%), 16 (1.87\%), and 178 (20.84\%) individuals, respectively. However, clades $\mathrm{A}, \mathrm{B}$, and $\mathrm{E}$ were most widely distributed in Eurasia, whereas 95.78\% of sampled Korean chickens fall into these clades. Accordingly, Korean chickens were domesticated from A (68.38\%) and B (6.56\%) clades from South China and Japanese chickens, whereas the $\mathrm{E}$ (20.84\%) clade is from the regions of Europe, the Middle East and the Indian subcontinent. In the clades, C (2.34\%) and D (1.87\%) were distributed from Japanese, Indian, and Indonesian regions. Most Korean chickens were involved in A clade, except Korean Ogye and Jeju breeds. Also, KNC (black, red and yellow) and commercial Woorimatdag chickens were found in the D clade. However, breed specific clades were not determined in our studies. Our mtDNA results indicated that the Korean chickens have same mtDNA haplotypes as chicken breeds from South China, Japan, Europe, the Middle East and the Indian subcontinent.

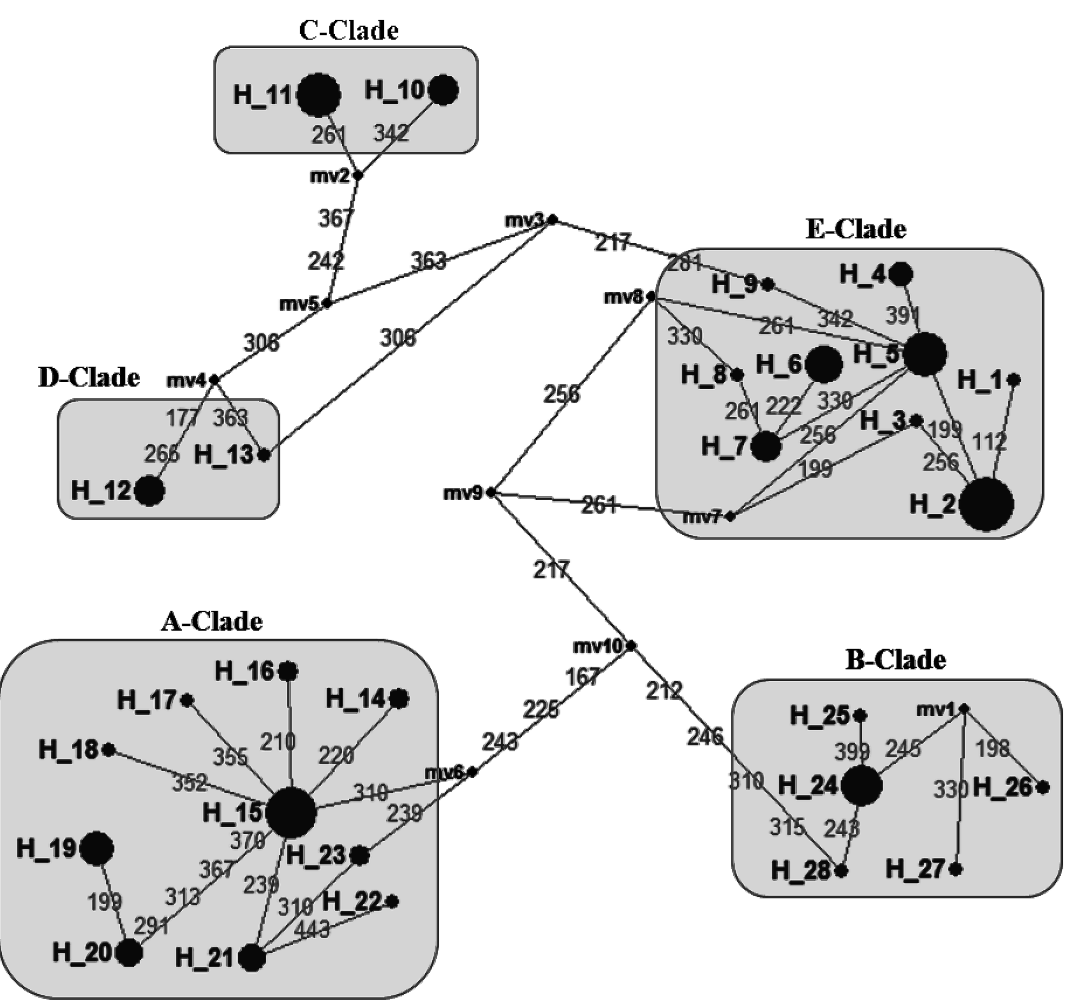

Fig. 2. Network profiles of the 28 haplotypes among the Korean chickens. The links are labeled by the nucleotide positions. The order of the mutations on the branch is arbitrary. The median vectors (mv) are nucleotide junctions. 
Table 3. Breed and population distribution in clades of Korean chickens

\begin{tabular}{|c|c|c|c|c|c|c|}
\hline Breed/Population & A-Clade & B-Clade & C-Clade & D-Clade & E-Clade & Total \\
\hline Rhode Island Red (RIR) & $98(70)$ & $8(5.71)$ & $1(0.71)$ & - & $33(23.57)$ & 140 \\
\hline Cornish & $27(32.53)$ & $38(45.78)$ & & - & $18(21.69)$ & 83 \\
\hline Korean native chicken black & $7(21.21)$ & - & $4(12.12)$ & $5(15.15)$ & $17(51.52)$ & 33 \\
\hline Korean native chicken red & $25(75.76)$ & - & $3(9.09)$ & $3(9.09)$ & $2(6.06)$ & 33 \\
\hline Korean native chicken yellow & $22(61.11)$ & - & & $1(2.78)$ & $13(36.11)$ & 36 \\
\hline Ogye & - & $6(18.75)$ & $9(28.13)$ & - & $17(53.12)$ & 32 \\
\hline White Leghorn & $1(100)$ & - & - & - & - & 1 \\
\hline Korean Long tail A & $1(100)$ & - & - & - & - & 1 \\
\hline Jeju & - & - & $1(33.33)$ & - & $2(66.67)$ & 3 \\
\hline Hyunin & $242(88.98)$ & $3(1.1)$ & - & - & $27(9.92)$ & 272 \\
\hline 5 Woorimatdag populations & $125(92.59)$ & $1(0.74)$ & - & $7(5.19)$ & $2(1.48)$ & 135 \\
\hline Parent stock of Woorimatdag (K) & $26(100)$ & - & - & - & - & 26 \\
\hline Hanhyup-3 & $8(20)$ & - & $2(5)$ & - & $30(75)$ & 40 \\
\hline Parent stock of Hanhyup-3 & $2(10.53)$ & - & - & - & $17(89.47)$ & 19 \\
\hline Total & $584(68.38)$ & $56(6.56)$ & $20(2.34)$ & $16(1.87)$ & $178(20.84)$ & 854 \\
\hline
\end{tabular}

Also, the results suggest that Korean chickens have multiple maternal origins and that domestications may have occurred in Eurasia and Southeast Asia.

In conclusion, Korean chickens were domesticated from a number of migrations of chicken breeds, and were adopted in Korea as pure breeds, which support the theory of multiple origins in Eurasia and Southeast Asia regions. Our results have identified haplotypes and clades based on geographical distribution, which will help the conservation of future breeding plans, and will improve Korean chickens.

\section{ACKNOWLEDGEMENTS}

This work was supported by a grant from the NextGeneration BioGreen 21 Program (No. PJ008133), Rural Development Administration, Republic of Korea.

\section{REFERENCES}

Aquadro, C. F. and B. D. Greenberg 1983 Human mitochondrial DNA variation and evolution: Analysis of nucleotide sequences from seven individuals. Genetics, 103: 287-312

Baker, A. J. and H. D. Marshall 1997 Mitochondrial control region sequences as tools for understanding evolution. In: Avian molecular evolution and systematic, Mindell D. P. ed. Academic press, (San Diego) pp. 51-82

Bandelt, H. J., P. Forster and A. Rohl 1999 Median-joining networks for inferring intraspecific phylogenies. Mol. Biol. Evol., 16: $37-48$

Cann, R. L., W. M. Brown and A. C. Wilson 1984 Polymorphic sites and the mechanism of evolution in human mitochondrial DNA. Genetics, 106: 479-499

Crawford, R. D. 1990 Origin and history of poultry species. Poultry genetic resources: evolution, diversity, and conservation. In: Poultry Breeding and Genetics, Crawford R. D. ed. Elsevier, (Amsterdam) pp. 1-59

Crawford, R. D. 1995 Origin, history, and distribution of commercial poultry. In: Poultry Production, Hunton P. ed. Elsevier, (Amsterdam) pp. 1-20

Delacour, J. 1957 The Pheasants of the World, $2^{\text {nd }}$ ed. Spue
Publications, Surrey, Hindhead

Fumihito, A., T. Miyake, S. Sumi, M. Takada, S Ohno and N. Kondo 1994 One subspecies of the red jungle fowl (Gallus gallus gallus) suffices as the matriarchic ancestor of all domestic breeds. Proc. Natl. Acad. Sci. U. S. A., 91: 12505-12509

Fumihito, A., T. Miyake, M. Takada, R. Shingu, T. Endo, T. Gojobori, N Kondo and S. Ohno 1996 Monophyletic origin and unique dispersal patterns of domestic fowls. Proc. Natl. Acad. Sci. U. S. A. 93: 6792-6795.

Hoque, M. R., N. R. Choi, H. Sultana, B. S. Kang, K. N. Heo, S. K. Hong, C. Jo and J. H. Lee 2012 Phylogenetic analysis of a privately-owned Korean native chicken population using mtDNA D-loop variations. Asian-Aust. J. Anim. Sci., (In press)

Hoque, M. R., K. C. Jung, B. K. Park, K. D. Choi and J. H. Lee 2009 Genetic Variability of mtDNA D-loop Region in Korean Native Chickens. Korean J. Poult. Sci. 37(4): 323-328

Hoque, M. R., S. H. Lee, K. C. Jung, B. S. Kang, M. N. Park, H. K. Lim, K. D. Choi and J. H. Lee 2011 Discrimination of Korean Native Chicken Populations Using SNPs from mtDNA and MHC Polymorphisms. Asian-Aust. J. Anim. Sci., 24(12): 16371643

Howard, R. and A. Moore 1984 A Compete Checklist of Birds of the World, revised ed. Macmillan (London)

Komiyama, T., K. Ikeo and T. Gojobori 2003 Where is the origin of the Japanese gamecock? Gene, 317: 195-202

Komiyama, T., K. Ikeo and T. Gojobori 2004 The evolutionary origin of long-crowing chicken: its evolutionary relationship with fighting cocks disclosed by the mtDNA sequence analysis. Gene, 333: 91-99

Lansman, R. A., J. C. Avise and M. D. Huettel 1983 Critical experimental test of the possibility of 'paternal leakage' of mitochondrial DNA. Proc. Natl. Acad. Sci. U. S. A., 80: 1969-1971

Lee, Y. J., M. S. A. Bhuiyan, H. J. Chung, W. Y. Jung, K. D. Choi, B. G. Jang, W. K. Paek, J. T. Jeon, C. S. Park and J. H. Lee 2007 Mitochondrial DNA diversity of Korean Ogol chicken. AsianAust. J. Anim. Sci. 20(4): 477-481

Liu, W. Y. and C. J. Zhao 2010 Comprehensive genetic analysis with mitochondrial DNA data reveals the population evolution relationships between Chinese Gamecocks and their neighboring native chicken breeds. Asian J. Anim. Vet. Adv., 5(6): 388-401

Liu, Y. P., G. S. Wu, Y. G. Yao, Y. W. Miao, G. Luikart, M. Baig, A. B. Pereira, Z. L. Ding, M. G. Palanichamy and Y. P. Zhang 2006 Multiple maternal origins of chickens: Out of the Asian jungles. 
Mol. Phylogenet. Evol., 38: 12-19

Moiseyeva, I. G. 1998 Ancient evidence for the origin and distribution of domestic fowl. In: Proceedings of the 10th European Conference, The Poultry Industry Towards the 21st Century (Jerusalem). I(21-28): 244-245

Moore, W. S. and V. R. Defilippis 1997 The window of taxonomic resolution for phylogenies based on mitochondrial cytochrome b. In: Avian molecular evolution and systematic, Mindell D. P. ed. Academic press (San Diego) pp. 84-119

Nei, M. 1982 Evolution of human races at the gene level. Prog. Clin. Biol. Res., 167-181

Nishibori, M., T. Shimogiri, T. Hayashi and H. Yasue 2005 Molecular evidence for hybridization of species in the genus Gallus except for Gallus varius. Anim. Genet. 36(5): 367-375

Niu, D., Y. Fu, J. Luo, H. Ruan, X. P. Yu, G. Chen and Y. P . Zhang 2002 The origin and genetic diversity of Chinese native chicken breeds. Biochemi. Genet., 40(5-6): 163-174
Oka, T., Y. Ino, K. Nomura, S. Kawashima, T. Kuwayama, H. Hanada, T. Amano, M. Takada, N. Takahata, Y. Hayashi and F. Akishinonomiya 2007 Analysis of mtDNA sequences shows Japanese native chickens have multiple origins. Anim. Genet., 38: $287-293$

Rozas, J., J. C. Sanchez-DelBarrio and X. Messeguer 2003 DnaSP, DNA polymorphism analyses by the coalescent and other methods. Bioinformatics, 19: 2496-2497

Tamura, K., D. Peterson, N. Peterson, G. Stecher, M. Nei and S. Kumar 2011 MEGA5: Molecular evolutionary genetics analysis using maximum likelihood, evolutionary distance, and maximum parsimony methods. Mol. Biol. Evol., 10: 1093

Thompson, J. D., D. G. Higgins, T. J. Gibson and W. Clustal 1994 Improving the sensitivity of progressive multiple sequence alignment through sequence weighting, position-specific gap penalties and weight matrix choice. Nucleic Acids Res., 22: 4673-4680 